\title{
KLASIFIKASI DAN ANALISIS DATASET KOMENTAR VIDEO YOUTUBE MENGGUNAKAN SUPERVISED LEARNING
}

\section{CLASSIFICATION AND ANALYSIS OF YOUTUBE VIDEO COMENT DATASET USING SUPERVISED LEARNING}

\author{
Finki Dona Marleny*1, Ihdalhubbi Maulida ${ }^{2}$, Bayu Nugraha ${ }^{3}$ \\ ${ }^{1,2}$ Informatika Fakultas Teknik Universitas Muhammadyah Banjarmasin \\ ${ }^{3}$ Sistem Informasi Fakultas Sains \& Teknologi Universitas Sari Mulia \\ E-mail:*finkidona@gmail.com
}

\begin{abstract}
ABSTRAK
Interaksi di dalam sosial media dapat di lihat dari komentar-komentar sebagai umpan balik dari setiap kegiatan yang ada di media sosial, mulai dari status yang berupa teks, gambar maupun video. Dari berbagai respon pada kolom komentar tersebut diperoleh sebuah informasi dari data yang tidak terstruktur sehingga perlu adanya suatu teknik untuk mendefinisikan nilai informasi Fokus dalam penelitian ini adalah untuk memverifikasi kebenaran dan menggali nilai informasi yang terstruktur sehingga dapat menggambarkan kejadian dan topik yang terhubung dari komentarkomentar yang ada di dalam video youtube yang menjadi objek penelitian ini. Dari hasil pengujian di atas dapat dilihat nilai performa dari hasil pengujian menggunakan metode Nä̈ve Bayes mendapatkan akurasi sebesar 57,50\%, sedangkan dengan menggunakan metode KNN mendapatkan akurasi $88.06 \%$.
\end{abstract}

Kata kunci:Youtube, Komentar, Klasifikasi, Video

\begin{abstract}
Interaction in social media can be seen from comments as feedback from every activity on social media, starting from status in the form of text, images and videos. From the various responses in the comments column, information is obtained from unstructured data so that there is a need for a technique to define the value of information. contained in the youtube video which is the object of this research. From the test results above, it can be seen that the performance value of the test results using the Nä̈ve Bayes method gets an accuracy of 57.50\%, while using the KNN method gets an accuracy of $88.06 \%$.
\end{abstract}

Keywords: Youtube, Coment, Classification, Video

\section{PENDAHULUAN}

Media sosial dan kebutuhan manusia modern saat ini tidak terlepas untuk saling berinteraksi, saling berbagi, sebagai fasilitas pembelajaran maupun hiburan. Interaksi di dalam sosial media dapat di lihat dari komentarkomentar yang tersedia di berbagai platform sebagai umpan balik dari setiap kegiatan yang ada di media sosial, mulai dari status yang berupa teks, gambar maupun video[1]. Dari komentar-komentar tersebut banyak terdapat opini yang terkadang positif maupun negatif, opini tersebut dapat dikaitkan dengan respon yang beragam, semakin banyak komentar maka semakin banyak pengguna yang berinteraksi, keadaan ini kadang menimbulkan interaksi yang memiliki respon tidak terduga. Dari berbagai respon pada kolom komentar tersebut diperoleh sebuah informasi dari data yang tidak terstruktur sehingga perlu adanya suatu teknik untuk mendefinisikan nilai informasi sehingga dapat lebih terstruktur. Dari data yang telah diestrak didapatkan suatu informasi tentang opini atau pendapat dari pengguna media sosial terhadap entitas tertentu[2].

Menganalisis pemantauan opini publik di Internet atau media sosial untuk pengumpulan informasi opini publik berupa 
analisis pencarian, pengelompokan informasi, analisis ucapan, dan analisis prediksi tren yang selanjutnya memverifikasi kebenaran dari nilai suatu informasi[3]. Informasi yang telah diproses dapat di kelompokan dan menggunakan berbagai Teknik pemrosesan teks salah satunya dapat dengan fitur ekstrasi teknik cross validation terhadap model Naïve bayes[4].

Dalam proses penggalian nilai suatu informasi yang terstruktur dan diproses dengan teknik tertentu agar pendapat yang memiliki nilai informasi tersebut bisa diolah dan dianalisa sehingga menghasilkan informasi yang bernilai dan dapat membantu banyak pihak dalam mengambil keputusan yang tepat yaitu dengan sentiment analisis yang merupakan studi komputasi mengenai pendapat, perilaku dan emosi seseorang terhadap entitas yang menggambarkan individu, kejadian atau topik[5].

Sedangkan untuk mengklasifikasikan kumpulan data komentar di video Youtube untuk analisis sentimen bisa menggunakan salah satu metode klasifikasi yaitu naive bayes[6]. Naive bayes merupakan algoritma yang digunakan untuk mencari nilai probabilitas tertinggi untuk mengklasifikasi data uji pada kategori yang paling tepat [7]. Metode sederhana ini juga merupakan salah satu metode kerja tercepat untuk analisis sentiment publik [8].

Fokus dalam penelitian ini adalah untuk memverifikasi kebenaran dan menggali nilai informasi yang terstruktur sehingga dapat menggambarkan kejadian dan topik yang terhubung dari komentar-komentar yang ada di dalam video youtube yang menjadi objek penelitian ini.

\section{METODOLOGI}

Klasifikasi dan analisis dataset komentar video youtube ini menggunakan tahapan Supervised Learning. Tahapan dalam metode yang digunakan adalah sebagai berikut:

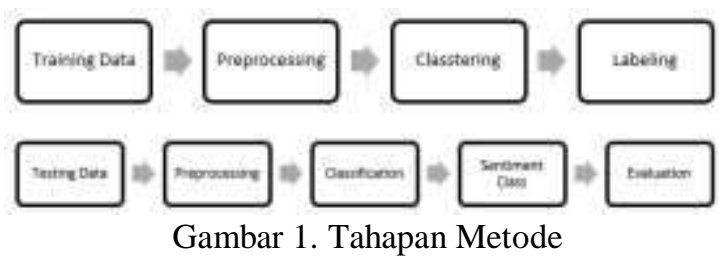

Sumber Data

Data yang di gunakan adalah data dari akun Youtube:
https://www.youtube.com/channel/UC91S7c1X OH-PILsaC0gem1g

Pada table 1 terdapat ID Video yang merupakan komentar video yang akan di analisis, kemudian ada jenis kelamin pengguna yang berkomentar menunjukan persentase komentar berdasarkan jeniskelamin ditiap video, selanjutnya usia pengguna yang mengomentari video tersebut.

Tabel 1. Sumber Dataset

\begin{tabular}{cccc}
\hline ID Video & Pria & Wanita & Usia \\
\hline 7DhgTS4gWdc & $40 \%$ & $60 \%$ & $24-34$ \\
VBJ2c4ptThw & $48,2 \%$ & $51,8 \%$ & $24-34$ \\
ehJldQV3bfs & $40 \%$ & $60 \%$ & $24-34$ \\
& & & $35-44$ \\
BAzWeuO9fiE & $48,1 \%$ & $51,9 \%$ & $24-34$ \\
\hline
\end{tabular}

\section{Preprocessing}

Dalam Tahap Preprocessing Data dilakukan beberapa tahapan proses, yaitu:

1. Case folding

Berfungsi untuk menyeragamkan bentuk huruf menjadi huruf kecil. Hal ini dilakukan untuk mempermudah pencarian. Tidak semua dokumen teks konsisten dalam penggunaan huruf kapital.

2. Tokenizing

Pada proses tokenization ini, semua kata yang ada di dalam tiap dokumen dipisahkan dan dihilangkan tanda bacanya, serta dihilangkan jika terdapat simbol atau apapun yang bukan huruf.

3. Stopword removal

Pada tahap ini, kata-kata yang tidak relevan akan dihapus, kata-kata yang tidak mempunyai makna tersendiri jika dipisahkan dengan kata yang lain dan tidak terkait dengan kata sifat yang berhubungan dengan sentimen.

4. Stemming

Stemming adalah proses pencarian kata dasar dengan menghilangkan imbuhan.

\section{Naïve Bayes}

Metode Naïve bayes dirumuskan sebagai berikut:

$P(A \mid B)=\frac{P(B \mid A) \cdot(A)}{P(B)}$

Data komentar yang terdapat pada metode ini akan direpresentasikan oleh pasangan atribut $\mathrm{x} 1, \mathrm{x} 2, \mathrm{x} 3, \ldots \mathrm{xn}$. Dimana $\mathrm{x} 1$ adalah kata pertama dari dokumen, $\mathrm{x} 2$ adalah kata kedua dan seterusnya. Metode Naive Bayes akan mencari 
probabilitas tertinggi untuk melakukan proses klasifikasi pada tweet yang akan diuji.

$$
\begin{gathered}
V_{M A P}=\underset{V_{j} e V}{\operatorname{argmax}} \prod_{n=1}^{n} P\left(x_{i} \mid V_{j}\right) P\left(V_{j}\right) \\
P\left(x_{i} \mid V_{j}\right)=\frac{n_{k}+1}{n+\mid \text { kosakata } \mid}
\end{gathered}
$$

\section{K-Nearest Neighbor}

Algoritma K-Nearest Neighbor (KNN) adalah sebuah metode untuk melakukan klasifikasi terhadap objek yang berdasarkan dari data pembelajaran yang jaraknya paling dekat dengan objek tersebut[10]. Kedekatan didefinisikan dalam jarak metrik, seperti jarak Euclidean. Jarak Euclidean dapat dicari dengan menggunakan persamaan berikut ini:

$$
D x y=\sqrt{\sum_{i=1}^{n}\left(x_{i}-y_{i}\right)^{2}}
$$

\section{HASIL DAN PEMBAHASAN}

Hasil Analisis komentar video dari peneltian ini dapat dibagi menjadi beberapa bagian pembahasan. Yaitu bagian proses dan hasil pengujian akurasi metode naïve bayes dan KNN.

Berikut ini adalah gambaran dari retensi penonton video yang akan diteliti.

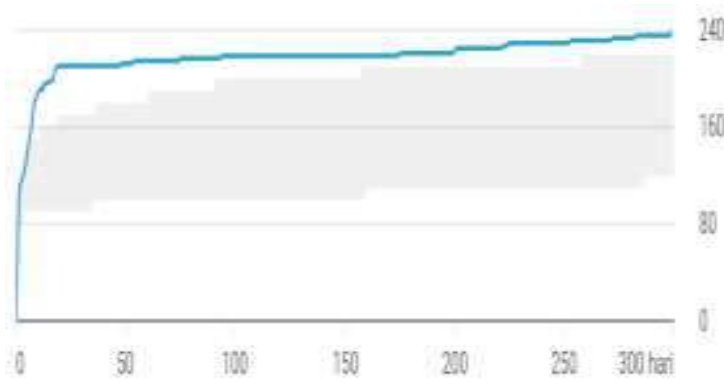

Gambar 2. Analisis Video ID : 7DhgTS4gWdc

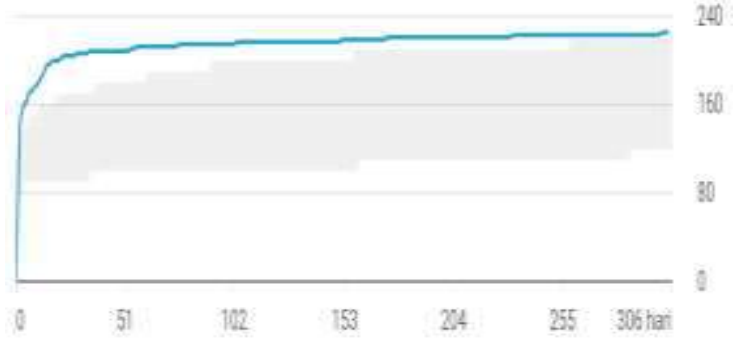

Gambar 3. Analisis Video ID:VBJ2c4ptThw

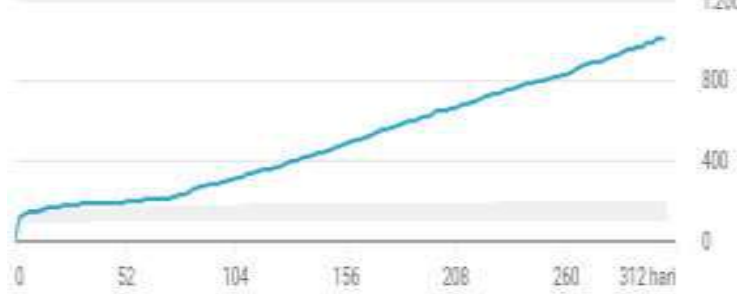

Gambar 4. Analisis Video ID : ehJldQV3bfs

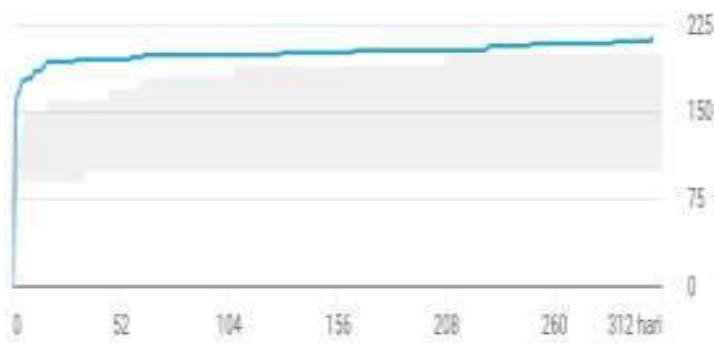

Gambar 5. Analisis VideoID: BAzWeuO9fiE

Grafik diatas menunjukan ringkasan jumlah penonton pada rentang waktu 312 hari dari awal unggahan video, video dengan ID: ehJldQV3bfs lebih banyak diminati.

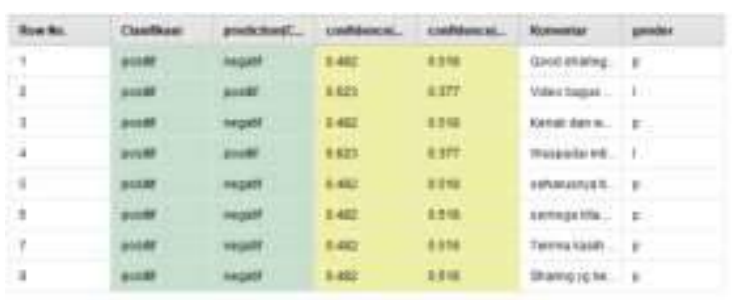

Gambar 6. Gambar klasifikasi prediksi

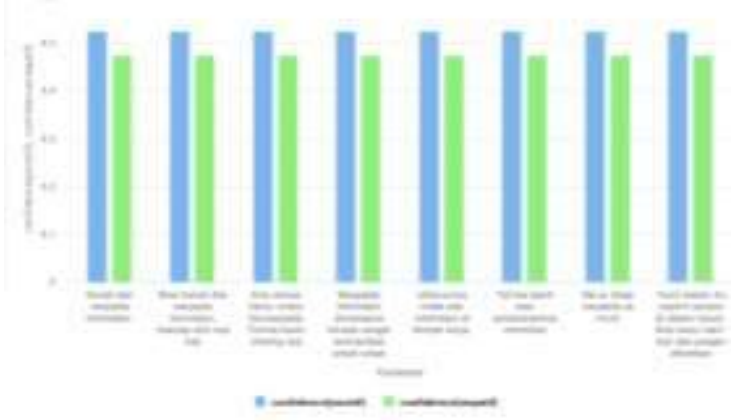

Gambar 7. Confidence Positif dan negative

grafik di atas menunjukan analisis sentiment positif dan negatif yang mana sudah mulai terlihat klasifikasi prediksi dari pengelompokan berdasarkan atribut komentar. Dari grafik diatas menunjukan confidence positif dan negatif, dari gambaran hasil diagram tersebut lebih dominan komentar positif. 


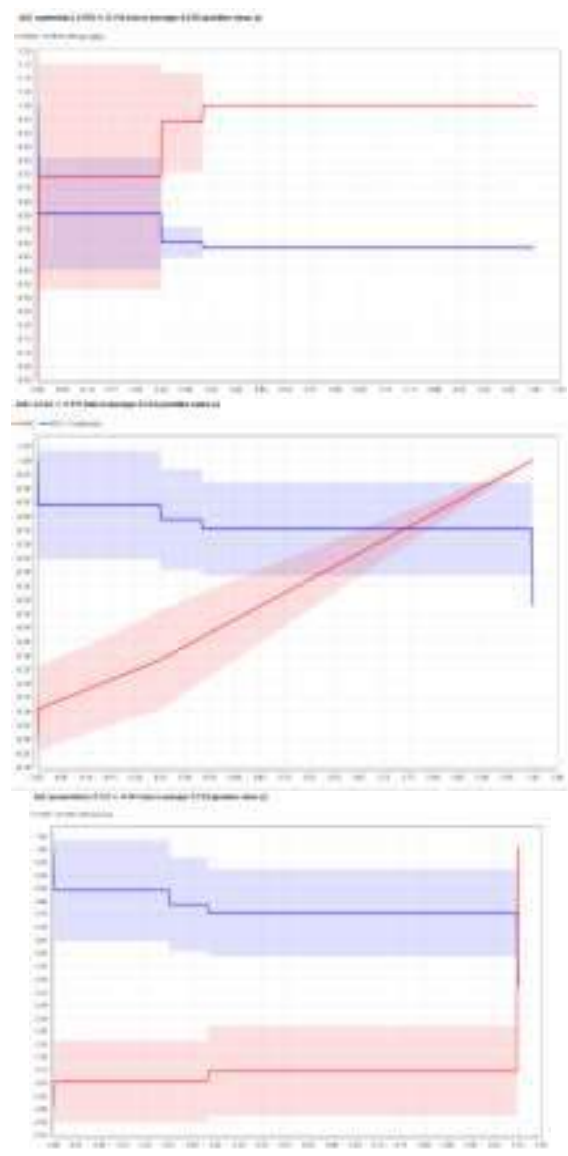

Gambar 8. AUC OPTIMISTIC naïve bayes

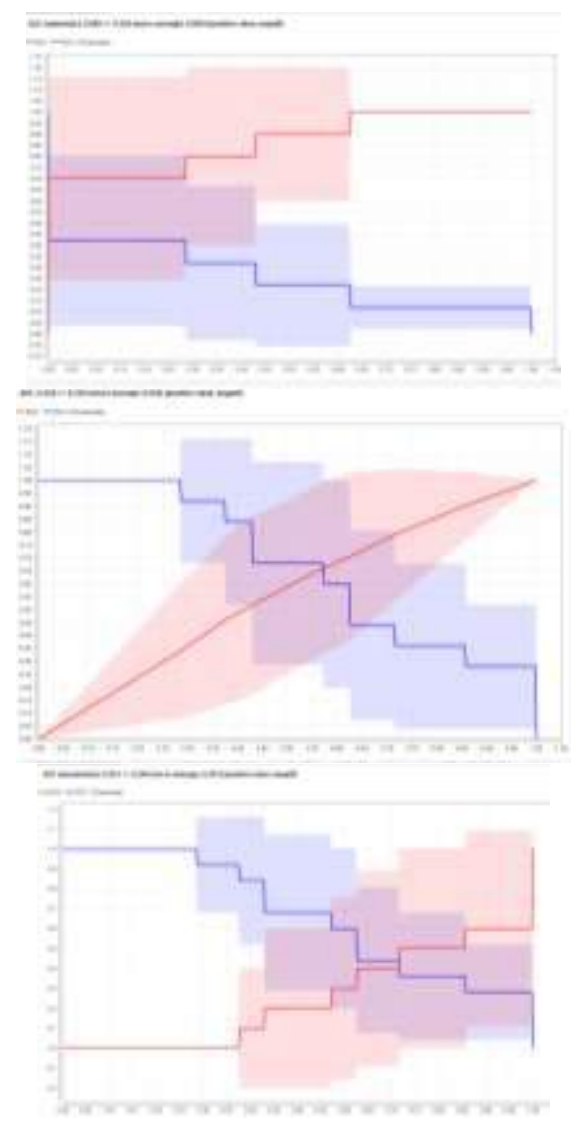

Gambar 9. AUC OPTIMISTIC KNN

\section{KESIMPULAN}

Pengujian dilakukan dengan membagi dataset dengan ratio 80\%:20\%. Proses akan diuji menggunakan metode Naïve Bayes dan KNN. Hasil pengujian akan ditunjukan dengan akurasi, confusion matrix, recall, dan presisi. Akurasi yang didapatkan menghasilkan seberapa dekat nilai prediksi dengan nilai sebenarnya. Berdasarkan pengujian di atas dapat dilihat nilai performa atau akurasi dari pengujian menggunakan metode Naïve Bayes mendapatkan akurasi sebesar 57,50\%, sedangkan dengan menggunakan metode KNN mendapatkan akurasi $88.06 \%$.

\begin{tabular}{|c|c|}
\hline Metode & Akurasi \\
\hline Naïve Bayes & $57.50 \%$ \\
\hline KNN & $88.06 \%$ \\
\hline
\end{tabular}

\section{SARAN}

Dalam pengujian yang dilakukan terdapat kesenjangan akurasi antara penggunaan metode KNN dan Naïve bayes, kesenjangan ini terjadi karena data latih yang di ujikan terlalu sedikit, sehingga hasil yang di proses kurang optimal, untuk mengoptimalkan hasil pengujian dapat menggunakan data komentar yang lebih banyak dan beragam sehingga pola data terlihat lebih terstruktur dan lebioh baik lagi.

\section{UCAPAN TERIMA KASIH}

Penulis mengucapkan terima kasih kepada semua pihak yang telah memberi dukungan terhadap penelitian ini.

\section{DAFTAR PUSTAKA}

[1] Marleny, F. (2020). ANALISIS

PENGGUNA WHATSAPP

TERHADAP KESALAHAN

MENGIRIM PESAN TEKS

MENGGUNAKAN METODE

KLASIFIKASI. Jurnal

Teknologi Informasi Universitas

Lambung

Mangkurat (JTIULM), 5(1), 19-24.

[2] Zy, A. T., \& Nugroho, A. 2018.

Comparison Algorithm

Classification Naive Bayes,

Decision Tree, and Neural Network for Analysis Sentiment. International Conference on 
Economic, Business, and Accounting, 1(c), 115-115.

$\mathrm{X}$. $\mathrm{Hu}$ and $\mathrm{C}$. Lu, "Research on Key Technologies of Internet Public Opinion

[3] Monitoring and Analysis System," 2018 IEEE 4th Information Technology and Mechatronics Engineering Conference (ITOEC), 2018, pp. 165-169, doi: 10.1109/ITOEC.2018.8740536

Yasah, K. S. (2020). Analisa Sentimen Tweet Indonesia Menggunakan Fitur

[4] Ekstrasi Dan Teknik Cross Validation Terhadap Model Naïve Bayes. Jurnal SIGMA, 10(4), 189-194.

Medhat, Walaa, Hassan, Ahmed, \& Korashy, Hoda, 2014, Sentiment Analysis

[5] Algorithms And Applications: A Survey, Ain Shams Engineering Journal (2014) 5, 1093-1113

Feldman, R and Sanger, J. 2007. The Text Mining Handbook: Advanced

[6] Feldman, R and Sanger, J. 2007. The Text Mining Handbook: Advanced Approaches in Analyzing Unstructured Data. Cambridge University Press:NewYork
[7] Byna, A., \& Basit, M. (2020). Penerapan Metode Adaboost Untuk Mengoptimasi Prediksi Penyakit Stroke Dengan Algoritma Naïve Bayes. Jurnal Sisfokom (Sistem Informasi dan Komputer), 9(3), 407-411.

[8] Susanto, A., Maula, M. A. I., Mulyono, I. U. W., \& Sarker, M. K. (2021). Sentiment Analysis on Indonesia Twitter Data Using Naïve Bayes and K-Means Method. Journal of Applied Intelligent System, 6(1), 40-45.

[9] Wu, J. (2012). Advances in $K$ means clustering: a data mining thinking. Springer Science \& Business Media.

[10] Shi, K., Li, L., Liu, H., He, J., Zhang, N., \& Song, W. (2011, September). An improved KNN text classification algorithm based on density. In 2011 IEEE International Conference on Cloud Computing and Intelligence Systems (pp. 113117). IEEE. 